\section{Assessment of Results}

In order to achieve a high degree of standardization a form was prepared and completed for each patient. In each case the results were assessed, after at least 18 months' treatment, by analys of the information contained in these forms. The results of treatment were classified as follows: "No benefit " means that the patient's condition had remained stationary or had become worse, as shown by a significant reduction in the walking distance before the onset of claudication, progression of the skin changes, or the presence of gangrenous ulceration. "Slight improvement" was considered to have taken place if the progress of the disease appeared to have been halted and if there was a slight but definite increase in the number of yards traversed before the onset of claudication. "Moderate improvement" means that after treatment the patient was able to walk at least half a mile further than had been possible before treatment.

The measurement of walking distance was carried out by the patients themselves, because experience has shown that this type of patient knows fairly accurately the distance that can be walked before claudication begins. It was impressed on all these patients that they must measure this distance (at their ordinary walking speed) in paces, each pace being taken as one yard.

After the trial had been in progress for about two and a half years, and all patients had received at least 18 months' treatment, it was closed and the result in each patient was assessed. Only then was I given the key to which patients had been on nicotinyl alcohol tartrate and which on placebo therapy. The results are shown in the table.

\begin{tabular}{c|c|c|c|c}
\multicolumn{5}{c}{ Results of Trial } \\
\hline Treatment & $\begin{array}{c}\text { No. of } \\
\text { Patients }\end{array}$ & $\begin{array}{c}\text { Moderate } \\
\text { Improvement }\end{array}$ & $\begin{array}{c}\text { Slight } \\
\text { Improvement }\end{array}$ & $\begin{array}{c}\text { No } \\
\text { Benefit }\end{array}$ \\
\hline $\begin{array}{c}\text { Nicotinyl alcohol } \\
\text { tartrate } \\
\text { Dummy tablets }\end{array}$ & 17 & 10 & 3 & 4 \\
\hline
\end{tabular}

Side-effects. - The only side-effect observed was mild flushing of the face in two of the 20 patients excluded from the final assessment of results.

\section{Discussion}

Intermittent claudication marks the beginning of the final stages of a slowly progressive arterial disease. After a given amount of exercise the intensity of the pain is so impressive and its onset so constant that the alleviation of this symptom is an obvious way of assessing the value of any drug used in treatment.

Because of the difficulty of making an unbiased assessment of "improvement" in such a chronic condition, it was felt to be essential to carry out a " blind" control trial, comparing the effect of nicotinyl alcohol tartrate with that of a placebo. In this disease it is difficult to compare the effect of any one drug with that of another by the application of the "blind" method, because of the large number of patients who would be required, so no such attempt was made. Further, with the use of such poor clinical material a large percentage of "rejects" can be expected, and thus relatively large numbers must be included initially, even when comparing one drug with placebo therapy, in order to obtain final figures which are sufficient for analysis. In the present trial it was found possible to include 50 patients within a relatively short time, and by these means it was hoped that a sufficient number would remain at the end of the trial to give significant results.

When comparing the numbers of patients who improved on nicotinyl alcohol tartrate with those on dummy tablets there can be no doubt that the patients on the active drug improved to a greater extent than did those on the placebo. The converse was also true that is. the number of patients failing to derive benefit from the active tablets was significantly smaller than the number of those who failed to receive benefit from the placebo.
It should be noted that statistical analysis takes no account of the fact that this is a progressive disease and is therefore no substitute for clinical experience. In the eyes of the clinician, a drug which halts the inevitable downward progress of the patient would be considered "beneficial," although, in the eyes of the statistician, a patient whose condition was unchanged at the end of 18 months would be considered to have received "no benefit."

\section{Summary}

A " blind" controlled trial is described in which 50 patients with severe intermittent claudication secondary to generalized arteriosclerosis were treated with nicotinyl alcohol tartrate or dummy tablets. Patients whose condition was complicated by the presence of other pathological processes were excluded. By the end of the trial the results of at least 18 months' treatment with nicotinyl alcohol tartrate (17 patients) and dummy tablets (13 patients) were available for comparison.

It was found that the results in those patients on the active drug were significantly better than in those who had received the placebo. It is therefore concluded that nicotinyl alcohol tartrate is a useful drug in the control of intermittent claudication.

The value of the "blind" method in a trial of this nature is discussed.

\section{REFERENCES}

1 Thurnherr, A., and Heller, H. (1949). Schweiz. med. Wschr., 79, 522 2 Brandman, O., and Redisch, W. (1950). J. med. Soc. N.J., 47, 267 White, S. M. (1950) Minn, Med 33,

4 Klausgraber, F. (1950). Wien. med. W schr., 100, 756.

Wien. med. W schr., 100, 756

Richter. I. Fogel, M. and Fabricant H (19S1). Ibid. 51, 1303

Texter. E. C., Redisch, W.. Shekman, E., Ferguson, S., and Steele, J. M.

Texter, B. C.. Redisch, W. Shekman,

8 Castro, C. M., and de Soldati, L. (1953). Angiology, 4, 165.

10 Fisher. $M$. M. and Tebrock, H. E. (1953).

\section{INTRAMEDULLARY NAILING FOR RECENT FEMORAL SHAFT FRACTURES}

BY

\author{
A. E. STEVENS, M.B., F.R.C.S.Ed. \\ Consultant Surgeon, Redhill County, Horsham, and \\ Dorking Hospitals \\ AND
J. PETT TURNEY, M.B., F.R.C.S. Formerly Senior Surgical. Registrar, Redhill County Hospital

During the past 16 years the insertion of intramedullary nails into the shafts of long bones has been done with increasing frequency. The method is not a new one, and in an extensive review of the difficulties of this form of treatment Watson-Jones and others (1950) discussed medullary nailing " after 50 years." They point out that Nicolayson in 1897 writes of the method, and Hey Groves (1918-19), in this country, described a number of cases, mostly of battle casualties from the first world war, treated in this way in 1916 and 1918. More recently, Küntscher (1940) has reintroduced the method, and there is now a vast amount of literature on the subject both on the Continent and in America. Böhler (1948) published his monograph on the method, dealing with 600 cases treated in his clinic, and the American Academy of Orthopaedic Surgeons (1951) surveyed 700 cases treated by 15 surgeons. 
Few reports, however, have been published in this country. Lloyd-Roberts (1951) reported 20 cases, and although many surgeons use the method the recorded cases are few.

\section{Material}

At the Redhill County Hospital in the past few years we have been making increased use of the method in recent fractures of the femoral shaft, and we here present a series of 41 cases which have been dealt with since December, 1948, although 30 have been treated since January, 1953, the most recent in February, 1956. There were 26 men and 15 women. The age distribution is shown in Table $I$. The site of the fracture in 8 cases was the

Table I.-Age Distribution

\begin{tabular}{c|c|c|c|c|c|c|c|c}
\hline $\begin{array}{c}\text { Age } . . \\
\begin{array}{c}\text { No. of } \\
\text { cases }\end{array}\end{array}$ & -19 & $20-29$ & $30-39$ & $40-49$ & $50-59$ & $60-69$ & $70-79$ & $80+$ \\
\hline
\end{tabular}

upper third, in 28 cases the middle third, and in 5 cases the lower third. Six were open fractures and 35 closed. Ten were pathological fractures, of which eight were due to Paget's disease of the bone and two to secondary carcinomatous deposits. All these patients were over 60 years of age. One patient who was operated on in June, 1954, had secondary carcinomatous deposits and two other deposits lower down the femur, without fracture. She is walking and the fracture has united. She has been treated with testosterone.

Union has occurred in all cases that were treated 12 or more months ago, except in one case, and we believe that the more recent cases will also unite satisfactorily.

Knee movements in cases which have united have also been very satisfactory. Table II shows the degree of knee

Table II.-Knee Movements in 34 Surviving Patients

\begin{tabular}{lll|l|c|c|c|c}
\hline $\begin{array}{l}\text { Degrees of movement } \\
\text { No. of cases }\end{array}$ &.. & $<$ & .30 & $30-$ & $60-$ & $90+$ & Full \\
\hline
\end{tabular}

movements obtained in the 34 cases that have been traced out of the 37 surviving patients. It is interesting to note that in the group of 10 patients who obtained indifferent knee movements - that is, less than $60^{\circ}$ - there were five of the eight cases of Paget's disease. Two more had ipsilateral fractures of the tibia, but in three no adequate reason was found for the limitation. In only two cases were hip movements restricted at all.

The average stay in hospital for all cases has been 84 days, which compares favourably with other forms of treatment, particularly when it is remembered that 18 of our patients were over the age of 60 and eight over the age of 80. One patient who.had facilities for being nursed at home was allowed out of hospital after 10 days, and started to walk six weeks after the operation.

It is interesting to note that the average stay in hospital of the last 12 patients operated upon was only 32 days and that three of them were octogenarians.

Four of our patients died in hospital. All were over the age of 70. One of these deaths was due to pulmonary embolus the day after operation; one patient with a pathological fracture due to secondary carcinoma died on the 37th day; and two patients died of bronchopneumonia and arteriosclerosis on the 37th and the 130th day. The cause of death in all cases was confirmed by necropsy. No patient has died since June, 1954, and all suitable cases admitted to hospital have undergone operation.

\section{Illustrative Cases}

A lorry driver aged 25 had a comminuted fracture of the mid-shaft of the left femur. Some difficulty was experienced in inserting the nail, but eventually good immobilization was obtained. He left hospital eight weeks after operation and, against advice, drove his two-ton lorry
12 weeks after the fracture. He eventually made a good recovery.

A factory hand aged 31 had a transverse fracture of the mid-shaft of the femur which was operated upon on July 30,1953 . He was in hospital for about 12 weeks and returned in May, 1954, complaining that he had slight limitation of abduction of the hip. On May 4 the nail was removed and it was found that consolidation was not complete and the leg bent in bed the next cay. On May 6 another nail was inserted, using a guide, and he eventually made a good recovery, although he did not rega in full knee movements.

A woman of 80 had an oblique fracture of the upper third. She was very agile for her age and started to walk six weeks after operation. She regained full knee movements, and union occurred within six months.

\section{Operation}

We have had no experience of the closed method of inserting the intramedullary nail, with $x$-ray control, as practised by Küntscher, but have exposed the fracture in all cases, and inserted the nail by the "retrograde" method described by Key and Connell (1951) and also used by Lloyd-Roberts. We have not used the modifications mentioned by Watson-Jones (1955).

If the fracture is a closed injury it may be convenient to immobilize the limb temporarily on a Thomas splint Pre-operatively it is important to have a knowledge of the length of nail required. A reasonably accurate working method is to hold one end of the nail against the sound greater trochanter and note how far short the other end is from the knee-joint. The width of the medullary canal on the film should also be observed, as occasionally it is abnormally narrow, especially in the middle third, and one of the complications is that the nail impacts into the medullary canal. This can be avoided by taking an $x$-ray picture of the femora with the nail strapped to the outside of the thigh and measuring the respective width of the nail and medullary canal. A more accurate method is to take scanogram measurements of the medullary canal, but this requires special apparatus.

Blood should be cross-matched in all cases, as in one case hammering on the nail caused shock profound enough to interrupt the progress of the operation. Blood transfusion has not, however, been necessary in every case, but it is wise to remember, as Ogilvie (1955) has stated, that "a man can bleed to death into the thigh muscles round a fractured femur without any free haemorrhage occurring."

It is advisable to have two assistants. If the fracture is an open one, operation within a few hours of the accident is imperative, and undressing and preparation of the patient may be deferred until anaesthesia is induced.

The patient is placed supine, with the injured side as near the edge of the table as possible. A flat sandbag is put under the buttock to tilt the patient towards the uninjured side. After skin preparations, the thigh is painied with "mastisol," and a sterile piece of tubular stockinet is rolled up the limb, which is then passed through the hole of an abdominal sheet. We find that this is a satisfactory method, insuring stable sterile cover while retaining maximum mobility.

If the tibia on the same side is fractured, we plate the tibia first, and then proceed to nail the femur. This occurred in four cases.

The ideal approach to the femur is that described by Henry (1945). An incision is made along the appropriate part of the line from the anterior superior iliac spine to the outer edge of the patella. The rectus and vastus lateralis muscles are identified by the V-shaped interval between them, a handsbreadth below the trochanter, and are separated. The vastus intermedialis muscle is divided lengthwise, cutting down to the bone. Often the incision can be modified to allow the routine treatment of the wound, but it may be more convenient to explore and close the wound before the normal approach is made. 
The upper fragment is then grasped with lion forceps by the operator and delivered from the wound in an adducted position. The first assistant controls the lower fragment while the second assistant adducts the leg strongly across the other. When full adduction has been gained the nail is inserted in the upper fragment and tapped upwards. Should it tend to become impacted it is wise to substitute a narrower nail.

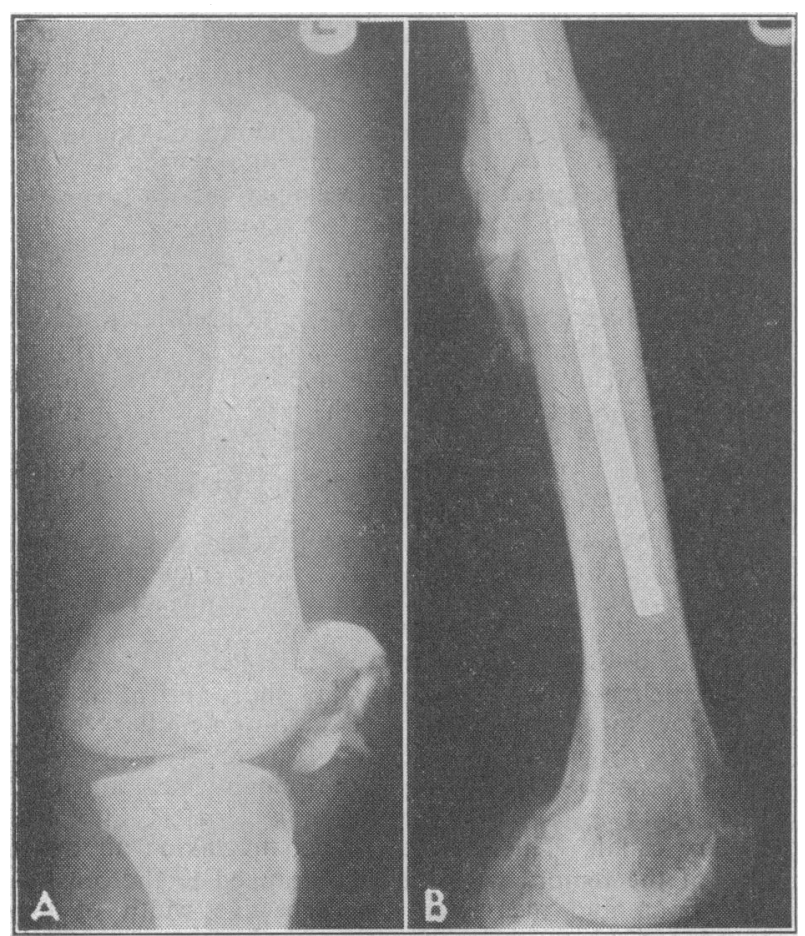

Fı. 1.-A: Showing slight comminution at fracture sitè and comminuted fracture of patella, which was excised. B: Same case, showing amount of callus formation eight weeks after operation. Patient had returned to work in an office.

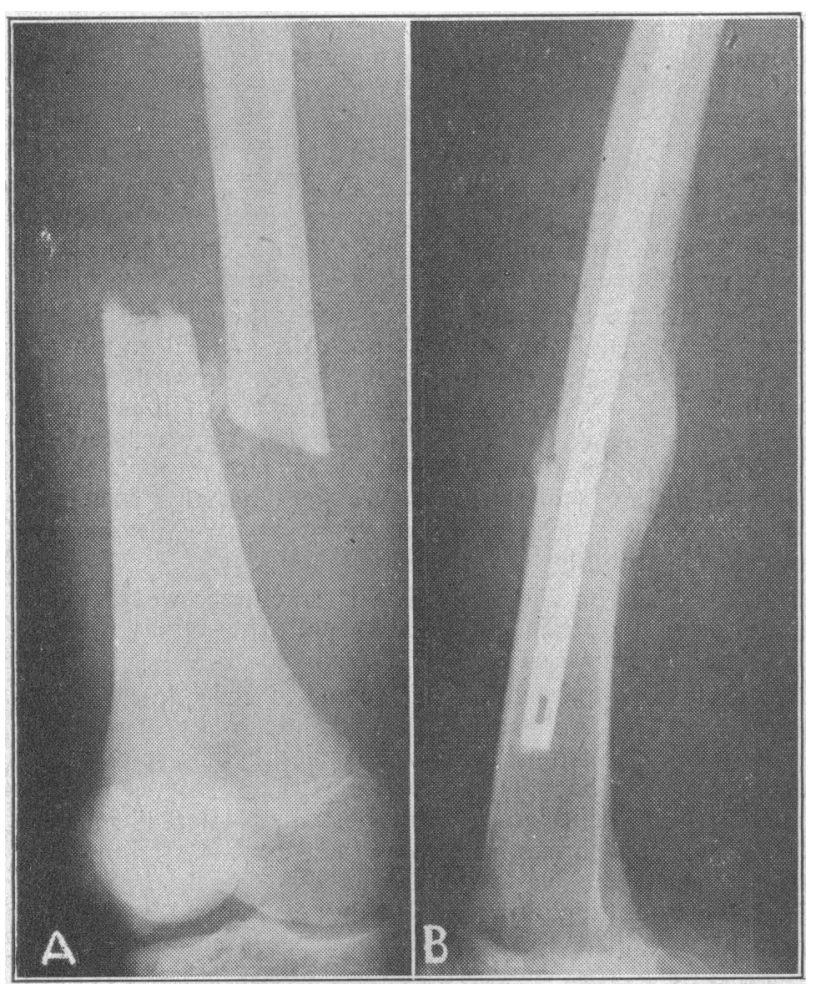

Fig. 2-A : Fracture of lower third of femur. B: Same case, showing amount of callus 12 weeks after operation.
We use a nail with an "eye" at both ends to facilitate its later removal. A sterile hacksaw is said to be a facesaving instrument if the nail becomes irretrievably impacted, but we have not had occasion to use one.

The resistance suddenly diminishes as the nail passes through the trochanter. The upper end of the nail can then be felt through the skin and glutei-muscles, and a 1-in. $(2.5-\mathrm{cm}$.) vertical incision is made over it. The nail is then tapped further upwards, and guided out of the upper incision with a blunt gouge, rather in the manner of a shoehorn, until the lower end is flush with the distal end of the proximal bone fragment. Full relaxation is now needed. The fracture is accurately reduced by temporarily diminishing the degree of adduction, and a large Lowman clamp, preferably with four blades, is applied. This, in the absence of much comminution, holds the fragments rigidly. The nail is then driven down into the distal fragment until no more than $\frac{1}{2}$ in. $(1.3 \mathrm{~cm}$.) protrudes from the trochanter. Careful watch is maintained that the fragments do not become distracted. Only the deep fascia and skin need to be closed, and the wound is covered with a non-encircling adhesive dressing.

Post-operatively the limb needs no external fixation as a rule, but if in comminuted cases it is felt that the internal fixation does not give complete immobility it is then

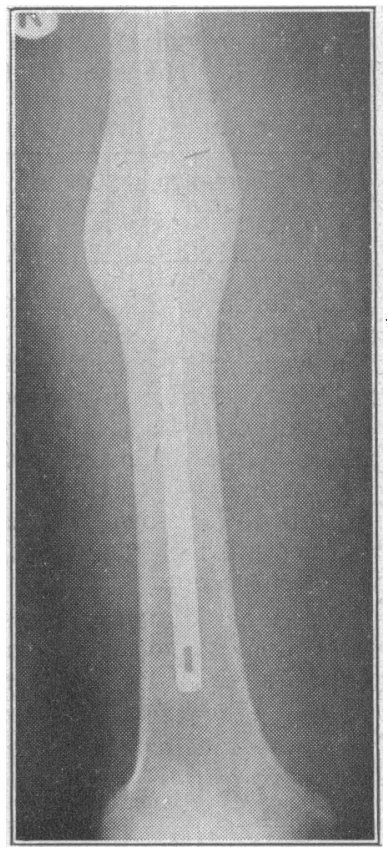

Fig. 3.-Transverse mid-shaft fracture; showing callus formation 12 months after operation.

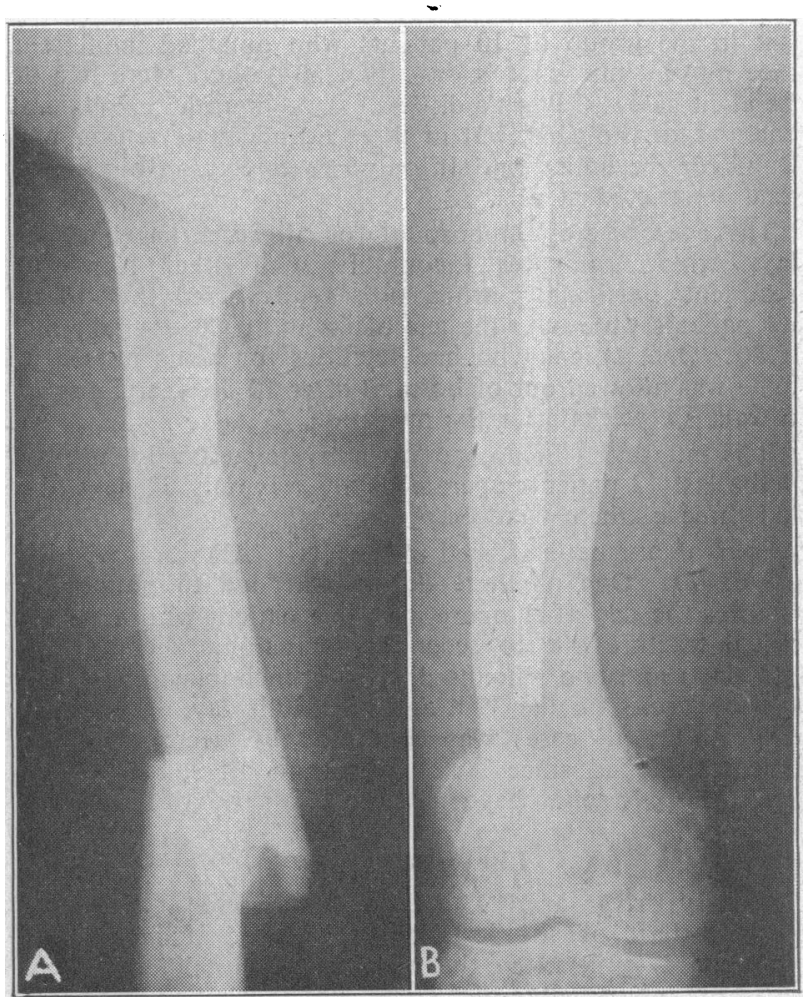

Frg. 4.-A: Transverse pathological fracture due to Paget's disease. B: Same case showing union 12 months after operation. 
necessary to rest the leg on a Thomas splint for some six weeks. Active exercises are enthusiastically encouraged and the patient is allowed to sit in a chair on the first postoperative day. Normally a young adult can lift his limb off the bed at the end of the first week, and can be discharged home when he is confident in the use of crutches. Weight-bearing is not generally allowed until there is good callus formation, but some of our patients with transverse fractures have borne weight after a fortnight.

\section{Complications}

Although Küntscher says " there is no complication of this method," both Böhler (1948) and Stuck and Thompson (1951), in addition to Watson-Jones, list a formidable number of complications and possible difficulties, ranging from instability of fixation to death from fat embolus. We have met with some but by no means all of these difficulties. Slow union has occasionally occurred, possibly because of slight distraction of the fragments. When one of our patients was seen nine months after the operation, he was complaining of pain on abduction of his leg, so the nail was removed. The next day the femur angulated in bed. The following day a larger nail was reinserted along a guide wire from above, and in a few days he was walking and working.

In another case of severe comminution of the femur it was found on $x$-ray examination after the operation that the nail had not penetrated the distal comminuted fragment, and a further exploration had to be done to correct this. The patient eventually made a satisfactory recovery.

In three other cases nails were removed because of upward displacement, but satisfactory union was obtained in all of them. One of these patients developed some sepsis in her wound, but this eventually cleared up completely. She was an obese diabetic, but did not develop any bone infection.

In the first case in our series the nail bent six weeks after insertion, and was removed at another hospital and a bone-grafting operation done. This case was poorly selected in that the fracture was too near the knee-joint.

In one patient with Paget's disease the nail bent during its insertion when its advancing end encountered sclerosed bone at the site of a previous fracture.

In one patient with Paget's disease, who was allowed to walk before the fracture was completely consolidated, the increased bowing of the femur has caused the nail to break in the centre. He is an old man of $80 ;$ he has been given a walking calliper, and manages to get about reasonably well. In other cases of Paget's disease the fracture has united satisfactorily.

In two cases calcification has occurred around the top of the nail above the great trochanter, presumably at the site of a previous haematoma. In both these cases a little pain was experienced, but after removal of the nail (in both cases about two years after the fracture) the pain has been relieved. Removing the hail was not a difficult procedure.

Although we do not advocate insertion of an intramedullary nail in children, we have used it in one case, with a satisfactory result, the nail being removed six months later. The fracture had united satisfactorily.

We have had two cases of wound sepsis; one necessitating removal of the nail, the other being a very superficial infection which did not delay progress.

\section{Discussion}

What are the indications for this method? We think that in adults all transverse fractures of the femoral shaft to within 4 in. $(10 \mathrm{~cm}$.) of the condyles can be treated with an intramedullary nail. Oblique fractures are not so well controlled as the transverse, but are satisfactory if the obliquity is not more than 3 to 4 in. (7.5 to $10 \mathrm{~cm}$.) in length. Comminuted fractures are also suitable, although the insertion of the nail is more difficult. Eight of our cases showed comminution, two to a serious degree.
The ideal patient is the young healthy adult man with a simple transverse fracture of the midshaft of the femur. In this type recovery is rapid, discomfort and immobilization are less than with other methods of treatment, callus formaiion is good, and knee movements often return to normal. The method is also of value in old people: in our series eight were over the age of 80 . Their nursing is facilitated by the absence of apparatus and splints.

We regard an open fracture seen six to nine hours after the causative accident as suitable for the insertion of a nail. Six of our cases were compound, and on no occasion have we regretted the treatment. In fact, in our hospital the only case of very delayed union after a fracture of the femur in the period under survey was early in this series when we were hesitant to use the technique on a compound fracture.

There is also a place for this method in the treatment of pathological fractures, and in our series there were 10 such. In cases of secondary carcinoma this method gives the patient an easier convalescence than is possible by other methods.

In difficult cases where the femur, tibia, and fibula are fractured on the same side, this is the ideal form of treatment if the tibia is plated at the same time. Four of our cases came into this category, one of them having compound comminuted fractures of the femur and of the tibia and fibula. He was able to return to work as a salesman in a multiple store 24 weeks after his accident.

\section{Conclusion}

Our experiences gained from the study of 41 cases of fracture of the shaft of the femur are presented. Watson-Jones gives a salutary warning that "this technique, if applied to improperly selected cases, or if inefficiently or unskilfully carried out, carries more possibility of trouble than any other." We would, however, like to add that we consider that in suitable cases it is at present the ideal form of treatment, and the overwhelming advantages outweigh the disadvantages, some of which we think have been exaggerated.

We are grateful to Mr. N. E. Pitt for allowing us to use the notes of one case operated on by him; to Dr. J. C. Cuthbert, medical superintendent of Dorking County Hospital, for the use of the notes of two cases which were treated at that hospital by one of us; and to Dr. E. Goldsmith for help in the translation of German papers.

REFERENCES

American Acaden y of Orthopaedic Surgeons (1951). Instructional Course Lectures, vol 8 . Ann Arbor.

Böhler, L. (1948). Medullary Nailing of Küntscher. Baillière, Tindall and Cox. London.

Groves, E. W. H. (1918-19). Brit. J. Surg., 6, 203.

Henry, A. K. (1945). Extensile Exposure, p. 101. Livingstone, Edinburgh Key, J. A. K. (1945). Extensile Exposure, p. 101. Livingstone, Edinburgh. cations, and Sprains, 5th ed., p. 947. Kimpton, London.

Kuntscher, G. (1940). Arch. klin. Chir., 200, 443.

Küntscher, G. (1940). Arch. klin. Chir., 200, 4

Ogilvie, H. (1955). Briti, $h$ Medical Journal, 1, 160.

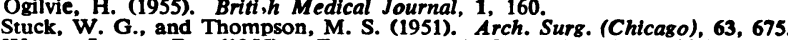
Watson-Jones, R. (1955). Fractures and Joint Injuries. Livingstone. Edinburgh.

et al. (1950). J. Bone Jt Surg., 32B, 694.

The Annual Report of the Institute of Almoners for 1955-6 records that during the year 9 students qualified as almoners through the course in medical social work at the University of Edinburgh, 11 through the Carnegie course in applied social studies at the London School of Economics, and 64 through the Institute's course. All 84 registered with the Institute, and 66 were already in permanent full-time employment when the report was prepared. In 1956 there was an increase of 28 in the total number of almoners employed. There has been a marked increase also in the number of hospitals employing almoners - 530 compared with 496 a year ago. The number of vacant posts for almoners is still very high, and the report remarks that it is a serious matter that many senior posts remain unfilled. It is hoped that the Whitley Council will have regard to this when considering almoners' salaries. 